\title{
EL USO DE LAS PLANTAS EN UNIDADES DOMÉSTICAS DEL SITIO ARQUEOLÓGICO PUNTA DE LA PEÑA 4, PUNA MERIDIONAL ARGENTINA
}

\author{
USE OF PLANTS IN DOMESTIC UNITS AT THE ARCHAEOLOGICAL SITE OF \\ PUNTA DE LA PEÑA 4, A PUNA IN SOUTHERN ARGENTINA
}

\author{
María Fernanda Rodríguez" ${ }^{1}$ Zulma E. Rúgolo de Agrasar ${ }^{1}$ y Carlos A. Aschero ${ }^{2}$
}

\begin{abstract}
El objetivo de esta investigación fue analizar el uso de los recursos vegetales -silvestres y cultivados-en el pasado prehistórico. Se estudiaron los restos vegetales recuperados en la capa 3, ca. 760-560 a.p., del sitio Punta de la Peña 4, ubicado en la localidad de Antofagasta de la Sierra, Catamarca, Argentina $-26^{\circ} 11^{\prime} 16^{\prime \prime}$ S y $67^{\circ} 20^{\prime} 51.3$ ” W- a una altura de $3.650 \mathrm{msm}$. Esta localidad pertenece a la Puna Meridional y, de acuerdo con las características ambientales y los patrones de comportamiento humano, se integra a la Puna Salada. Los objetivos específicos fueron identificar las especies vegetales halladas; discutir el posible uso de las mismas teniendo en cuenta el contexto de recuperación y la información etnobotánica, y evaluar la importancia relativa de las especies cultivadas dentro de la economía doméstica. La identificación del material arqueológico se realizó por comparación anatómica y morfológica a partir de material actual. Se identificaron semillas y frutos de especies cultivadas de los géneros Chenopodium, Phaseolus y Zea, restos de gramíneas silvestres del género Deyeuxia acompañadas por otras especies herbáceas. Este es el primer hallazgo de cultivos (macrovestigios) en el área y es interesante destacar su asociación con especies silvestres en la capa 3 del sitio.
\end{abstract}

Palabras claves: recursos vegetales, registro arqueobotánico, Puna, paleoambiente, Chenopodium, Phaseolus, Zea, Deyeuxia.

The use of vegetable resources - both native and cultivated - in the prehistoric past were analyzed from botanical remnants recovered at the archaeological site of Punta de la Peña 4, layer 3, dated to ca. 760-560 B.P. The site is located near the village of Antofagasta de la Sierra, Catamarca, Argentina (26 $16^{\prime} 16^{\prime \prime} \mathrm{S}$ and $\left.67^{\circ} 20^{\prime} 51.3^{\prime \prime} \mathrm{W}\right)$ at an altitude of $3,650 \mathrm{~m}$. It is part of the Southern Argentinean Puna (basin in the higher Andes) and due to environmental characteristics and human behavior patterns, it is regarded as part of the Salty Puna. Besides identifying specific plant species from the site, the authors discuss possible uses of these species considering the recovered context at the archaeological site and ethnobotanical information. Also an evaluation was made of the relative importance of cultivated plant species for the domestic economy. The comparative anatomical and morphological analyses of present day and archaeological plants allowed for the identification of the latter. Seeds and fruit of cultivated species of the genera Chenopodium, Phaseolus and Zea as well as the remains of native grasses, such as Deyeuxia and other herbaceous plant species, were identified. This is the first discovery of cultigens (macroremains) in the area, and the relationship between these and native species in layer 3 is interesting.

Key words: Plant species resources, archaeobotanical record, Puna, paleoenvironment, Chenopodium, Phaseolus, Zea, Deyeuxia.

En este trabajo se investigó el uso de los recursos vegetales en el pasado prehistórico en la Puna Meridional Argentina. En este sentido, fue importante considerar la asociación espacial de los mismos dentro de unidades domésticas, así como también la presencia de especies cultivadas y su relación con especies silvestres en el contexto arqueológico. Para esto se analizaron los macrovestigios vegetales recuperados en la capa 3 (lentes a/d), ca. 760-560 a.p., del sitio Punta de la Peña 4 (PP4), ubicado en las inmediaciones de la localidad de Antofagasta de la Sierra, Provincia de Catamarca (Figura 1a).

En esta capa se hallaron restos de gramíneas silvestres y semillas y frutos de especies cultivadas. Estos hallazgos permiten discutir la posibilidad de que se trate de especies no locales, es decir, cultivadas en zonas de menor altitud y llevadas

\footnotetext{
1 Instituto de Botánica Darwinion. Labardén 200. CC 22. 1642, San Isidro, Provincia de Buenos Aires, Argentina. frodriguez@darwin.edu.ar; zrugolo@ darwin.edu.ar

2 Instituto de Arqueología y Museo, Universidad Nacional de Tucumán, San Martín 1545, 4000, San Miguel de Tucumán, Argentina. ascherocarlos@yahoo.com.ar
} 


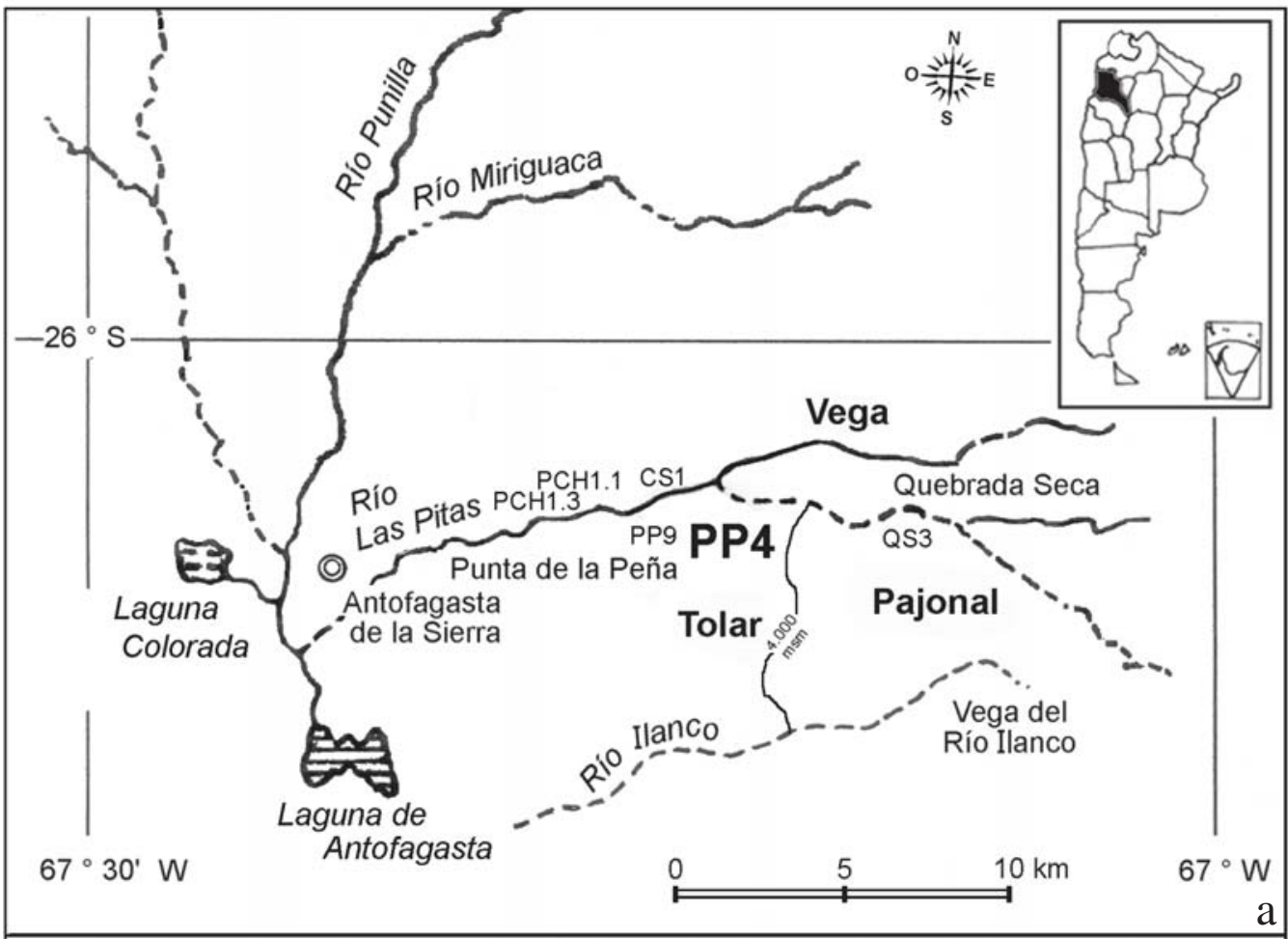

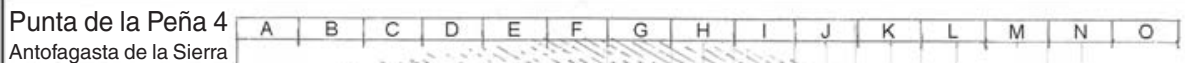

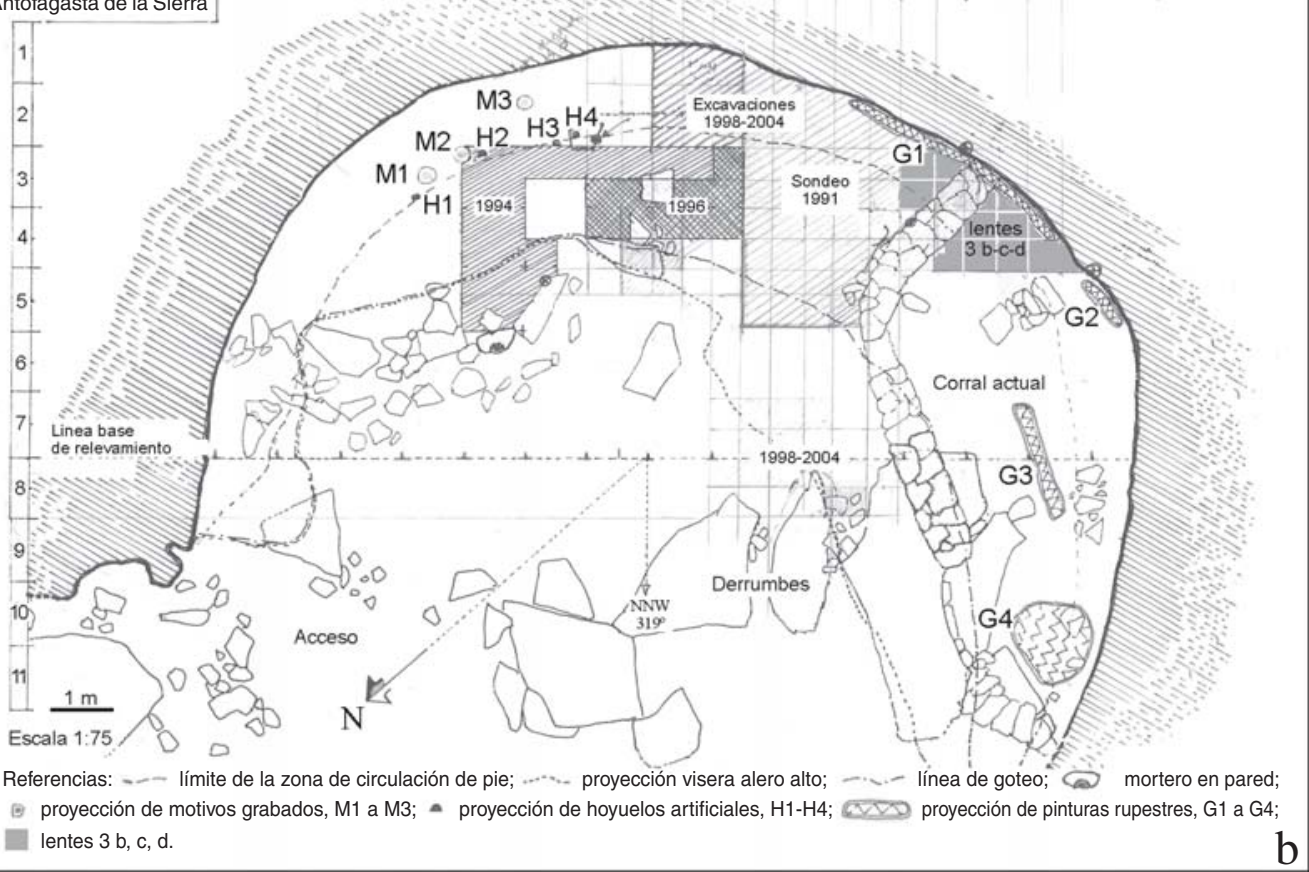

Figura 1. (a) Localidad de Antofagasta de la Sierra, Catamarca, Argentina. Sitios arqueológicos Punta de la Peña 4 (PP4), Peñas Chicas 1.1 (PCH1.1), Peñas Chicas 1.3 (PCH1.3), Punta de la Peña 9 (PP9), Cueva Salamanca (CS1) y Quebrada Seca 3 (QS3). (b) Planta del sitio PP4 (C.A. Aschero).

(a) Location of Antofagasta de la Sierra, Catamarca, Argentina. Punta de la Peña 4 (PP4), Peñas Chicas 1.1 (PCH1.1), Peñas Chicas 1.3 (PCH1.3), Punta de la Peña 9 (PP9), Cueva Salamanca 1 (CS1) and Quebrada Seca 3 (QS3) archaeological sites. (b) Plant from PP4 archaeological site (C.A. Aschero). 
luego a la Puna o alternativamente que alguna de ellas implique prácticas particulares de tratamiento de los frutos y semillas que refuerzan la idea de un prolongado tiempo de producción local.

La lente a/d de la capa 3 presenta una interesante asociación entre especies cultivadas y silvestres. Esta asociación y la presencia de cultivos no habían sido registradas hasta el momento en otros sitios arqueológicos del área de estudio. Esto plantea una nueva perspectiva en el uso de los recursos vegetales, a pesar de que, aun tratándose de momentos tardíos (ca. 760-560 a.p.), estos cultivos no constituyeron elementos centrales en la dieta alimentaria de los grupos humanos que habitaron el área, sino más bien un complemento dentro de una economía basada aún en la caza y la recolección. Esta economía habría continuado en el área durante todo su poblamiento, ca. 10.000-400 a.p., teniendo en cuenta las fechas más tempranas obtenidas en sitios tales como Quebrada Seca 3, ubicado en el curso medio-superior del río Las Pitas y las más tardías obtenidas en el sitio en estudio.

El énfasis de esta investigación se puso en las plantas consideradas recursos para la subsistencia de los grupos humanos. Para el área de Antofagasta de la Sierra fue posible definir las tres asociaciones vegetales con especies vegetales útiles para los grupos que la habitaron: pajonal, tolar y vega (Figura 1a). Rossen y Ramírez (1997:107) proponen el concepto de "planta económica" aquella que tiene utilidad potencial para el hombre, directa o indirectamente, ya sea como alimento, medicina, construcción o combustible, y a la vez delimitan microzonas en donde crecen estas especies.

El objetivo general de este trabajo fue analizar el uso de los recursos vegetales -silvestres y cultivados- en el lapso ca. 760-560 a.p. Los objetivos específicos: identificar las especies vegetales halladas; discutir el posible uso de las mismas teniendo en cuenta el contexto de recuperación y su asociación en la capa 3 y la información etnobotánica disponible, y evaluar la importancia relativa de las especies cultivadas dentro de la economía doméstica.

\section{Antecedentes de las Especies Domésticas en el Área de Antofagasta de la Sierra}

En el área de Antofagasta de la Sierra se determinó la presencia de granos de almidón, silicofitolitos y cristales de calcio de semillas de Chenopodium cfr. quinoa (Babot 2005a, 2005b), en artefactos de molienda procedentes de niveles arqueológicos $2 \mathrm{~b} 3$ y $2 \mathrm{~b} 2$ del sitio Quebrada Seca 3 (QS3), ubicado en el curso medio-superior del río Las Pitas (Babot 2004: Tabla 7.4). Estos niveles tienen dataciones radiocarbónicas de ca. 4.7004.500 a.p. Es importante aclarar que no es posible atribuir con seguridad la especie al género Chenopodium a partir de granos de almidón; sin embargo se observaron afinidades con la quínoa -Chenopodium quinoa- (Babot 2005a).

Según las determinaciones realizadas por Babot (2004), en el artefacto de molienda $\mathrm{N}^{\mathrm{o}} 15$ -nivel 2b2 de QS3 (4.510 \pm 100 a.p.)- se presenta la asociación de Chenopodium cfr. quinoa, con granos de almidón de Zea mays. En este artefacto se agregan silicofitolitos de fruto de Opuntia sp. y de corteza de fruto de Cucurbita sp. junto con granos de almidón de tubérculos no identificados (Babot 2005a). En el artefacto $N^{\circ} 41$-nivel 2b3 de QS3 (4.770 \pm 80 a.p.) - se recuperaron también silicofitolitos de Opuntia sp. y Cucurbita sp., además de hojas y pecíolo de hoja de Acrocomia sp. También en esta pieza hay polen de la familia Poaceae y silicofitolitos de la familia Cyperaceae que resultan de interés por la asociación arqueológica de la capa 3, lente 3b de PP4 (Babot 2004). Acrocomia sp. es una especie de palmera de la selva basal Oranense -situada a más de $500 \mathrm{~km}$ de distancia- cuyas fibras se han utilizado en cordelería desde ca. 8.400 a.p. (Hocsman et al. 2004; Rodríguez 1999a; Rodríguez y Aschero 2005a).

En el área de estudio también se recuperaron silicofitolitos de Phaseolus sp. y de otras especies de la familia Fabaceae en artefactos de molienda de los sitios Quebrada Seca 3 y Cueva Salamanca 1, en niveles datados en ca. 6.000 a.p. Otros microvestigios de Chenopodium cfr. quinoa (Babot 2005a), Zea mays y Phaseolus vulgaris se hallaron en los sitios Peñas Chicas 1.1 (3.590 \pm 55 a.p., LP 263, carbón), Peñas Chicas 1.3 (ca. 3.400 a.p.) y Punta de la Peña 9 (ca. 1.460-530 a.p.) (Babot 2004). Por último, en el nivel 2 del sitio Peñas Chicas 1.3 (3.490 \pm 60 a.p.) fueron recuperados tallos de Chenopodium quinoa (Aguirre 2005). Estos sitios se hallan muy próximos a PP4, en el curso medio-inferior del río Las Pitas.

\section{Área de Estudio}

Troll (1958) divide a la Puna, teniendo en cuenta las características ambientales y los patrones de 
comportamiento humano, en seca, salada y húmeda. Antofagasta de la Sierra se encuentra en la Puna Salada, sector meridional hiperárido, con grandes salares y escasos cursos de agua (Cabrera 1976). Desde el punto de vista fitogeográfico, el área de estudio pertenece a la Provincia Puneña del Dominio Andino en donde la vegetación dominante es la estepa arbustiva (Cabrera 1976; Cabrera y Willink 1980). Por encima de los $3.800 \mathrm{msm}$, se desarrolla un pastizal de gramíneas tales como Festuca sp., Jarava sp. y Deyeuxia sp., con especies subarbustivas de los géneros Adesmia (Fabaceae), Baccharis (Asteraceae), Parastrephia (Asteraceae) y Fabiana (Solanaceae); corresponde a la asociación vegetal del pajonal. Por debajo de los 3.800 msm comienza el tolar, en donde abundan especies de Parastrephia (Asteraceae) y Acantholippia (Verbenaceae). El cauce del río Las Pitas se caracteriza por presentar una cubierta de gramíneas y juncáceas que conforman la vega (Rodríguez 1999a, 1999b, 2000) (Figura 1a).

\section{Descripción del Sitio Punta de la Peña 4}

El sitio PP4 es un abrigo rocoso de $15 \times 7 \mathrm{~m}$ ubicado en el curso medio-inferior del río Las Pitas, a $26^{\circ} 11^{\prime} 16^{\prime \prime}$ S $-67^{\circ} 20^{\prime} 51.3$ " W y a una altura de $3.650 \mathrm{msm}$; se encuentra en la asociación vegetal del tolar y a una distancia de $5 \mathrm{~km}$ hacia el este comienza el pajonal (Figura 1a).
En el sitio se distinguieron dos sectores de reparo constituidos por un alero superior y uno inferior, ambos con arte rupestre (Figura 1b). Los fechados radiocarbónicos, ca. 8.900-460 a.p., indican una ocupación durante el Holoceno Temprano, Medio y Tardío. Se diferenciaron 8 capas estratigráficas: 0a, 0b, 1-7 (Rodríguez et al. 2003).

Los fechados radiocarbónicos (Rodríguez et al. 2003) señalan la siguiente ocupación del sitio PP4: una unidad estratigráfica 7 con una datación de $8.970 \pm 60$ a.p., que fue cortada por una estructura de cavado que alcanzó el piso de roca del alero, destinada a conformar una amplia área de habitación estimada en unos $25 \mathrm{~m}^{2}$, de la que se han excavado $16 \mathrm{~m}^{2}$. Tal estructura contiene las que fueron designadas capas 5 y 6 con dataciones entre $4.100 \pm 60$ a.p. y $3.250 \pm 50$ a.p. La capa 4 cubre todos estos niveles de ocupación y tiene una datación de 3.870 \pm 90 a.p. En la zona media-base otra datación de $460 \pm 70$ a.p. corresponde al fogón de las ocupaciones tardías que afectó la porción cumbral de la capa (Tabla 1).

La capa suprayacente $3 x$ es una lente de ca. $8 \mathrm{~m}^{2}$ con un fogón playo datado en $3.820 \pm 100$ a.p. Las capas 3, 2 y 1 corresponden a niveles de ocupación tardía selladas por una potente capa de "guano" formada por fecas de camélidos, ovinos y cápridos. Estos niveles de ocupación tardía fueron datados entre ca. 740 a 460 a.p. (530 \pm 80 a.p., capa 3 bajo alero- $540 \pm 40$ a.p., capa 2 ). Se produjeron

Tabla 1. Estratigrafía del sitio PP4.

PP4 archaeological site stratigraphy.

\begin{tabular}{lcl}
\hline \multicolumn{1}{c}{ Capa/Extracción } & Datación radiocarbónica años a.p. & \multicolumn{1}{c}{ Material utilizado } \\
\hline Capa 7 & $8.970 \pm 60$ & Carbón \\
Capa 6 (3) 2 $2^{\text {a extracción }}$ & $4.120 \pm 60$ & Carbón y madera parcialmente quemada \\
Capa 6 (3) 2 extracción & $3.250 \pm 50$, AMS & Hueso de camélido \\
Capa 4b (1a) & $4.060 \pm 90$ & Carbón \\
Capa 4a (zona media-base) & $3.870 \pm 90$ & Madera \\
Capa3, fogón en c.4a cumbre & $460 \pm 70$ & Carbón \\
Capa 3x & $3.820 \pm 100$ & Carbón \\
Capa 3, bajo alero & $530 \pm 80$ & Camadas de gramíneas \\
Capa 3, lente 3d & $760 \pm 40$, UGA-15089, AMS & Semillas de quínoa \\
Capa 3, lente 3b & $690 \pm 50$, UGA-15090, AMS & Semillas de quínoa \\
Capa 3, lente 3b & $560 \pm 50$, UGA-15088, AMS & Cariopsis de maíz No 109 \\
Capa 3, fogón bajo alero & $470 \pm 50$, UGA-9265 & Carbón \\
Capa 2 & $540 \pm 40$ & Camadas de gramíneas \\
Capa 1 de un basural exterior & $960 \pm 40$ & Carbón \\
\hline
\end{tabular}


limpiezas sucesivas de pisos de ocupación expuestos, con acumulación de residuos en la zona externa del alero, cuya porción cumbral fue datada por una muestra de carbón en 960ะ40 a.p. (carbón de vaciado de fogón correspondiente a la capa $1 \mathrm{del}$ basural exterior (Tabla 1).

En este trabajo interesa la capa 3 y sus subdivisiones por la asociación recuperada entre distintos restos vegetales. Estas subdivisiones se denominan lentes, debido a su reducida extensión y están delimitadas en la zona bajo reparo del interior del alero (Figura 1b). En la misma se obtuvieron nuevas dataciones por Accelerator Mass Spectrometry (AMS) sobre quínoa y maíz, que figuran en la Tabla 1 con la sigla y el número correspondientes.

$\mathrm{Al}$ avanzar en el decapage de la capa $3 \mathrm{x}$, en el sector SW de la zona bajo reparo, se detectó una zona con menor compactación de los sedimentos y una estratifícación de niveles arenosos conteniendo distintas estructuras de combustión y de vaciado de fogón. El resultado de las dataciones por AMS y la comparación de los vestigios obtenidos con los de la capa 3 del alero mostraron que esta estratificación correspondía a distintos momentos de ocupación ocurridos posteriormente a la formación de la capa 3x. Dentro de una posible estructura estos momentos de ocupación no pudieron ser claramente establecidos por la baja compactación de los sedimentos arenosos. Pero esta interestratificación de la capa 3, lentes 3a-3d, fue claramente reconocida en una superficie de $5,50 \mathrm{~m}^{2} \mathrm{y}$ con un espesor variable entre 17 y $21,5 \mathrm{~cm}$.

La lente 3a presentó una estructura de combustión con contorno de piedras conteniendo sólo ceniza. Analizando la estructura del sitio, se determinó que esta lente se corresponde estratigráficamente con la capa 3 de los otros sectores de la excavación.

En cambio, la lente 3b, que no tiene equivalente en otros sectores, presentó otra estructura de combustión de iguales características: sólo cenizas, trozos de arcilla a medio cocer y abundantes semillas de quínoa. De aquí proceden las muestras UGA 15090 (interior del fogón) y UGA 15088 (grano de maíz del exterior del fogón) (Tabla 1). En la lente más profunda de $3 \mathrm{~d}$ se recuperaron semillas de quínoa asociadas nuevamente con una estructura de combustión, en este caso, un fogón playo, sin borde de piedras. Las semillas proceden de la zona de dispersión carbonosa -sin ceniza- y proporcionaron la datación UGA 15089 (Tabla 1, Figura 1b).

\section{Materiales y Métodos}

La excavación del sitio, dirigida por C. Aschero desde el año 1996 (previo sondeo en el año 1991) hasta el presente, se realizó por decapage sectorial siguiendo capas naturales y la microtopografía de la matriz de apoyo de artefactos y ecofactos. Esto permitió obtener un plano detallado de la distribución de ecofactos y artefactos. Las unidades estratigráficas o capas, según los casos, pudieron ser subdivididas -como en el caso de la capa 3- según cambios en la compactación o en la coloración de la matriz. La superposición de artefactos o ecofactos en planta determinó la realización de dos o más extracciones. El cambio hacia una nueva subdivisión y extracción implicaba el inicio de un nuevo plano. Luego de un estudio de la posición de los artefactos en la matriz (horizontales y oblicuos o "clavados") y controles de migración vertical, u otros procesos postdepositacionales, pudieron establecerse distintos niveles de ocupación del sitio (Figura 1b).

Las unidades de excavación fueron cuadrículas de 1 x $1 \mathrm{~m}$, cada una dividida en microsectores de $50 \times 50 \mathrm{~cm}$, que operaron como unidades de embolsado. Se excavó una superficie total de $3,50 \mathrm{~m}^{2}$ que abarcó 14 microsectores. Dentro de la capa 3 se realizaron distintas extracciones que permitieron dividirla en $3 \mathrm{x}, 3 \mathrm{y}, 3 \mathrm{z}$; los volúmenes excavados en cada una fueron de: $472.300 \mathrm{~cm}^{3}(3 \mathrm{x})$, $175.000 \mathrm{~cm}^{3}$ (3y) y $87.500 \mathrm{~cm}^{3}(3 \mathrm{z})$.

Las plantas y los perfiles estratigráficos se dibujaron en escala 1:10, utilizando un sistema de rastras que cubrieran la posibilidad de mapeo de la gran variabilidad de vestigios minerales y orgánicos presentes, particularmente en las capas 1 a 3 del sitio (Figura 1b). La separación de microvestigios del sedimento del sitio se realizó con un arnero de malla de $12 \mathrm{~mm}$ considerando la diagonal de cada cuadrado del mismo. En el campo se separó todo el material, el cual fue procesado íntegramente en el laboratorio. Hasta el momento no se han aplicado técnicas de flotación, se espera realizar este tipo de análisis en las próximas campañas.

Se destaca la excelente conservación del material hallado, debido a las condiciones áridas del 
sitio y a la ausencia de perturbación postdepositacional. Las especies vegetales fueron recuperadas en las lentes a/d de la capa 3, que continúan la sucesión estratigráfica del sitio. Varias de las semillas y frutos hallados fueron datados por AMS. La muestra botánica analizada consistió en una semilla de poroto, una semilla de Prosopis sp., 110 semillas de quínoa y seis cariopsis de maíz. Estos aparecieron acompañados por una elevada cantidad de gramíneas (ca. de 600 ramas floríferas) y otros tres especímenes herbáceos.

La identificación de las especies herbáceas (Figuras 2-6) se realizó por comparación anatómica y morfológica a partir de los ejemplares de la colección de referencia, conformada por especies coleccionadas en el área de estudio, siguiendo transectas a partir de los sitios arqueológicos (Rodríguez 2004). Las especies coleccionadas fueron identificadas y depositadas en el herbario (SI) del Instituto de Botánica Darwinion (Holmgren et al. 1990). La colección de referencia mencionada fue ampliada con material de dicho herbario. A partir de los ejemplares de referencia, se confeccionó la histoteca que contiene los cortes histológicos de las especies actuales. Las gramíneas también pudieron ser identificadas taxonómicamente, ya que se hallaron grandes cantidades de ramas floríferas con espiguillas (Figura 2).

Para llevar a cabo el estudio anatómico se realizaron cortes transversales a mano alzada de es- pecies actuales y arqueológicas (D'Ambrogio de Argüeso 1986; Rodríguez 1996-1998). Los preparados histológicos fueron coloreados con safranina y fotografiados con microscopio óptico NIKON FX-A (Figura 6). Para la identificación anatómica se consideraron los siguientes caracteres diagnósticos: forma-contorno del tallo o de la hoja, epidermis (simple, estratificada), esclerénquima (número de capas, distribución, tipo), parénquima (abundante o no, tipo de células), clorénquima (distribución), haces vasculares (distribución, vainas que los rodean).

La identificación de las semillas fue posible por comparación morfológica con material actual conservado en el herbario SI. Se observaron y analizaron bajo lupa binocular (Wild MS) y se fotografiaron (Figura 3), teniendo en cuenta los caracteres: forma, tamaño y color de las semillas y/o frutos, cotiledones, embrión, hilo y radícula de las semillas.

Los cariopsis de maíz fueron identificados por la Ing. Agr. A. M. Miante Alzogaray (Facultad de Agronomía, UBA). Parte del material arqueológico, incluyendo algunas semillas, fue analizado y fotografiado con microscopio electrónico de barrrido (Phillips XL-30) en el Museo de Ciencias Naturales de Buenos Aires Bernardino Rivadavia (Figuras 4-5). Por último, se tomaron fotografías de los conjuntos de ramas floríferas con cámara digital NIKON-Coolpix 950 (Figura 2).
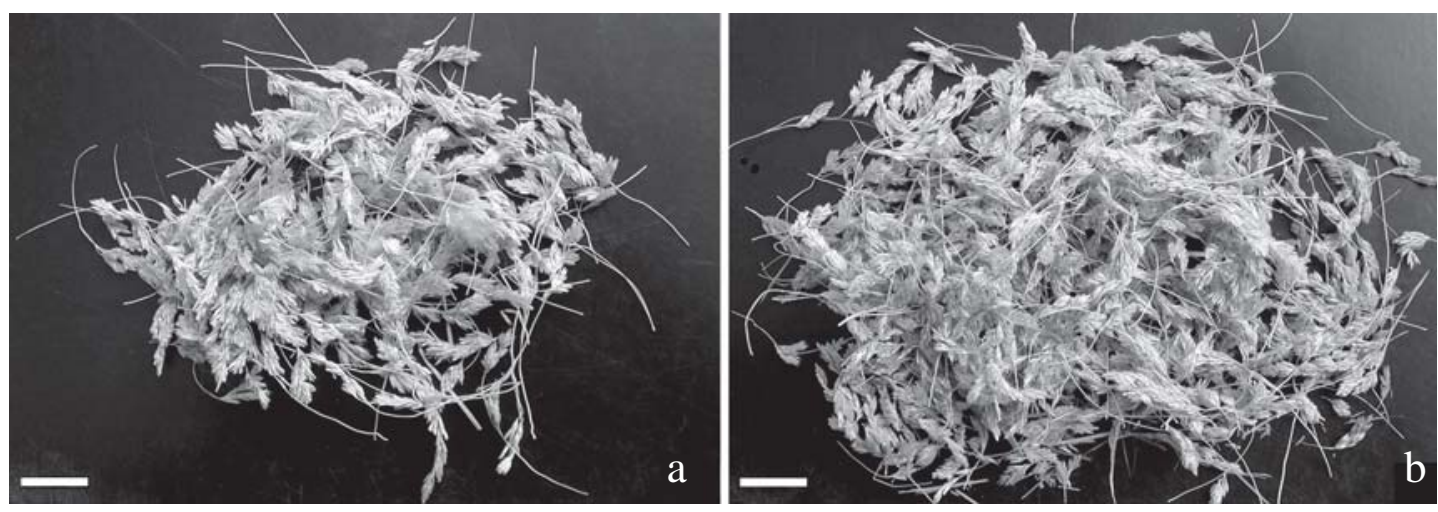

Figura 2. Conjuntos de ramas floríferas con espiguillas recuperados en la capa 3 del sitio PP4. (a) ramas floríferas aglomeradas con vellones de lana de camélido ( $\mathrm{N}^{\circ} 75$, microsector L4C); (b) ramas floríferas ( $\mathrm{N}^{\circ} 107$, microsector L4B). Las reglillas equivalen a $20 \mathrm{~mm}$.

Flowering branches and spikelets were recovered in layer 3, PP4 archaeological site. (a) Flowering branches agglomerated with tufts of camelid fleece ( $N^{o} 75$, microsector L4C); (b) flowering branches ( $N^{o} 107$, microsector L4B). Rules $=20 \mathrm{~mm}$. 


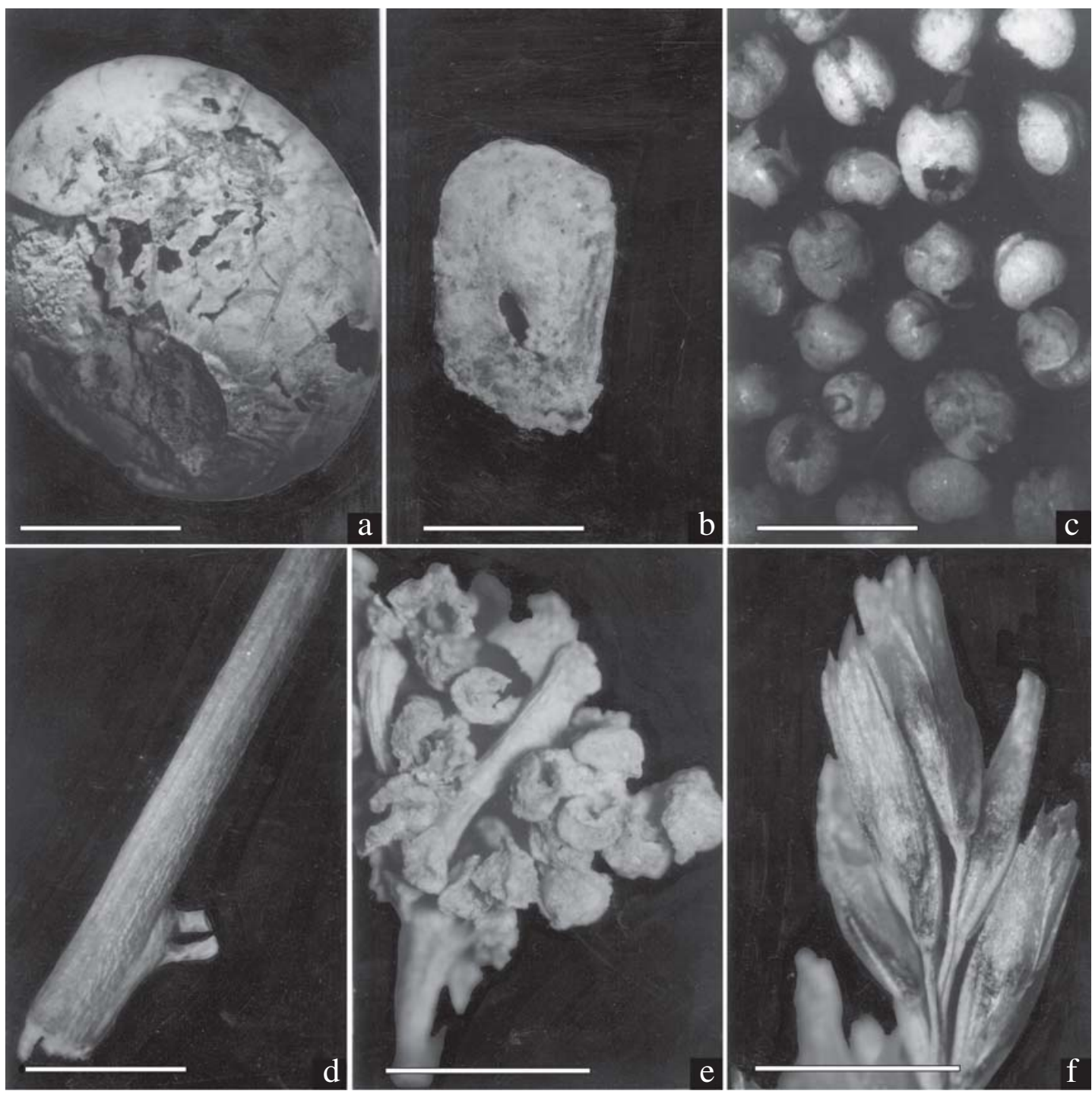

Figura 3. Microfotografías tomadas con lupa binocular. Material arqueológico. (a) Phaseolus vulgaris, semilla ( $\mathrm{N}^{\circ} 68$, microsector M3C); (b) Prosopis sp., semilla ( ${ }^{\circ}$ 68, microsector M3C); (c-d) Chenopodium quinoa: (c) semillas ( $\mathrm{N}^{\circ}$ 906, microsector L3C); (d) rama florífera ( $\mathrm{N}^{\circ} 68$, microsector M3C); (e) Deyeuxia eminens var. fulva, rama florífera ( $\mathrm{N}^{\circ} 68$, microsector M3C). Las reglillas equivalen a $5 \mathrm{~mm}$.

Photographs take with the aid of a steriomicroscope. (a) Phaseolus vulgaris, seed ( $N^{o} 68$, microsector M3C); (b), Prosopis sp., seed $\left(N^{o}\right.$ 68, microsector M3C); (c-d) Chenopodium quinoa: (c) seeds ( $N^{o} 906$, microsector L3C); (d) flowering branch ( $N^{o} 68$, microsector M3C); (e) Deyeuxia eminens var. fulva, flowering branch ( $N^{o} 68$, microsector $\left.M 3 C\right)$. Rules $=5 \mathrm{~mm}$.

\section{Material actual examinado}

- Chenopodium quinoa Willd. Argentina. Prov. de Jujuy, Depto. Humahuaca, Humahuaca, semillas de cultivo, 1933, A.E. Marino 96 (SI).

- Chenopodium quinoa Willd. Argentina. Prov. de Jujuy, Depto. Humahuaca, Humahuaca, especie cultivada, $3.000 \mathrm{msm}$., 20-V-1942, A.T Hunziker 2099 (SI).
- Deyeuxia eminens J. Presl. var. eminens. Argentina. Catamarca, Depto. Antofagasta de la Sierra: ruta 53, Vega de Los Colorados, 3750 msm, 18-II-1980, Cabrera et al. 31818 (SI); Antofagasta de la Sierra, 3.400 msm, 5-II1946, Cabrera 8944 (BAA); Paicuqui, sobre el río Punilla, 3.300 msm, IV-1958, Vervoorst 717 (LIL). 

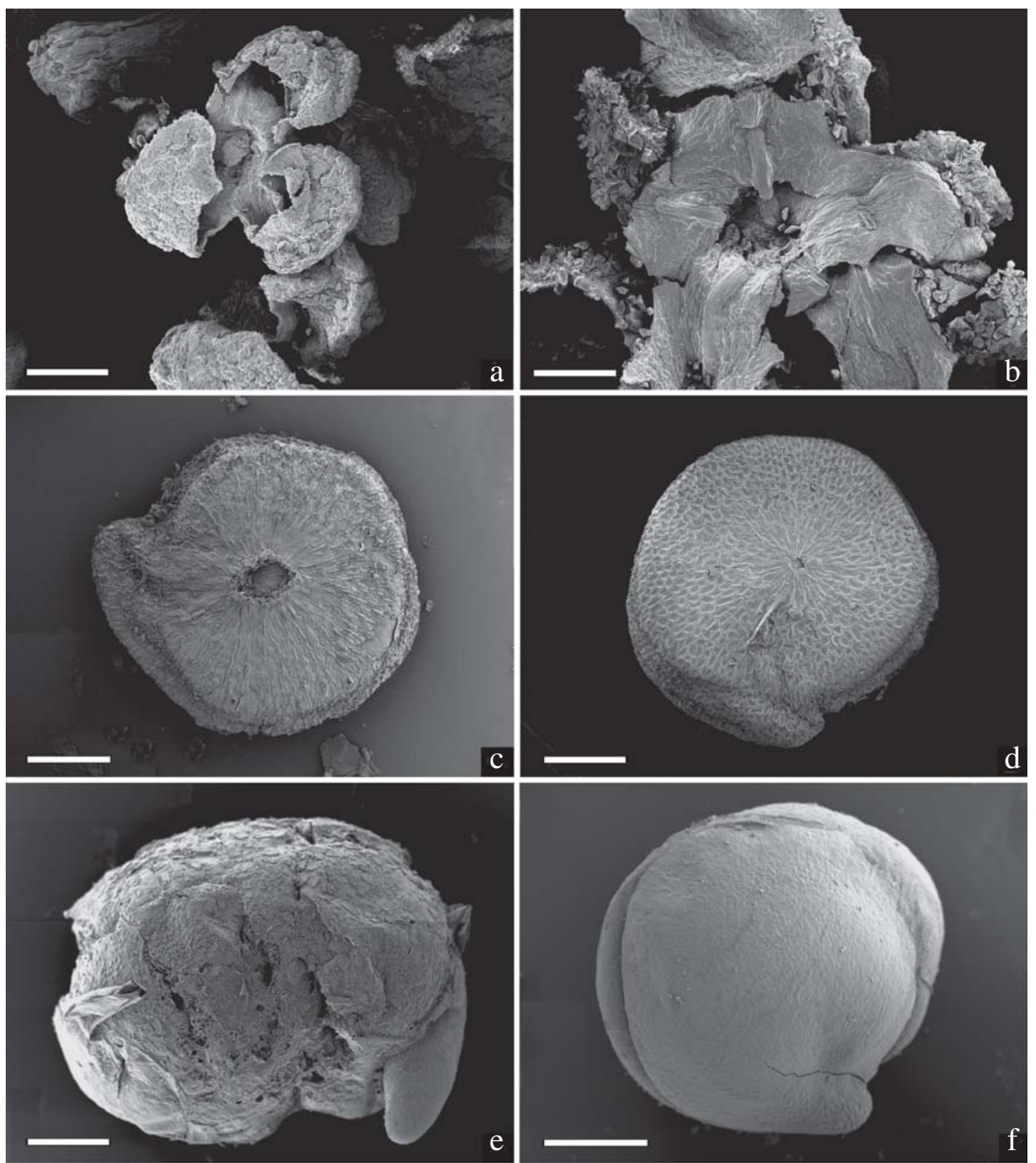

Figura 4. Chenopodium quinoa. Microfotografías tomadas con microscopio electrónico de barrido. (a-b). Rama de una inflorescencia: (a) detalle del perianto sin el fruto, nótese la superficie cubierta de pelos vesiculosos, material actual de referencia, A. T Hunziker 2099 (SI); (b) restos del perianto sin el fruto, material arqueológico ( $N^{\circ}$ 68, microsector M3C). (c-f). Semillas: (c) material actual de referencia, semilla con tegumento, A.E. Marino 96 (SI); (d-f) material arqueológico ( $\mathrm{N}^{\circ}$ 68, microsector M3C): (d) semilla con tegumento; (e) semilla sin tegumento, se observa la radícula; (f) semilla con tegumento, nótese el embrión curvo. Las reglillas equivalen a $500 \mu \mathrm{m}$.

Chenopodium quinoa. Scanning electron micrographs. (a-b) Stem of inflorescence: (a) detail of the perianth without fruit, observe the surface covered with vesicular hairs, present day reference material, A.T. Hunziker 2099 (SI); (b) perianth remains without fruit, archaeological material ( $N^{o} 68$, microsector M3C). (c-f) Seeds: (c) present day reference material, seed with tegument, A.E. Marino 96 (SI); (d-f) archaeological material ( $N^{o} 68$, microsector M3C): (d) seed with tegument; (e) seed without tegument and rootlet; $(f)$ seed with tegument and curved embryo. Rules $=500 \mu \mathrm{m}$. 

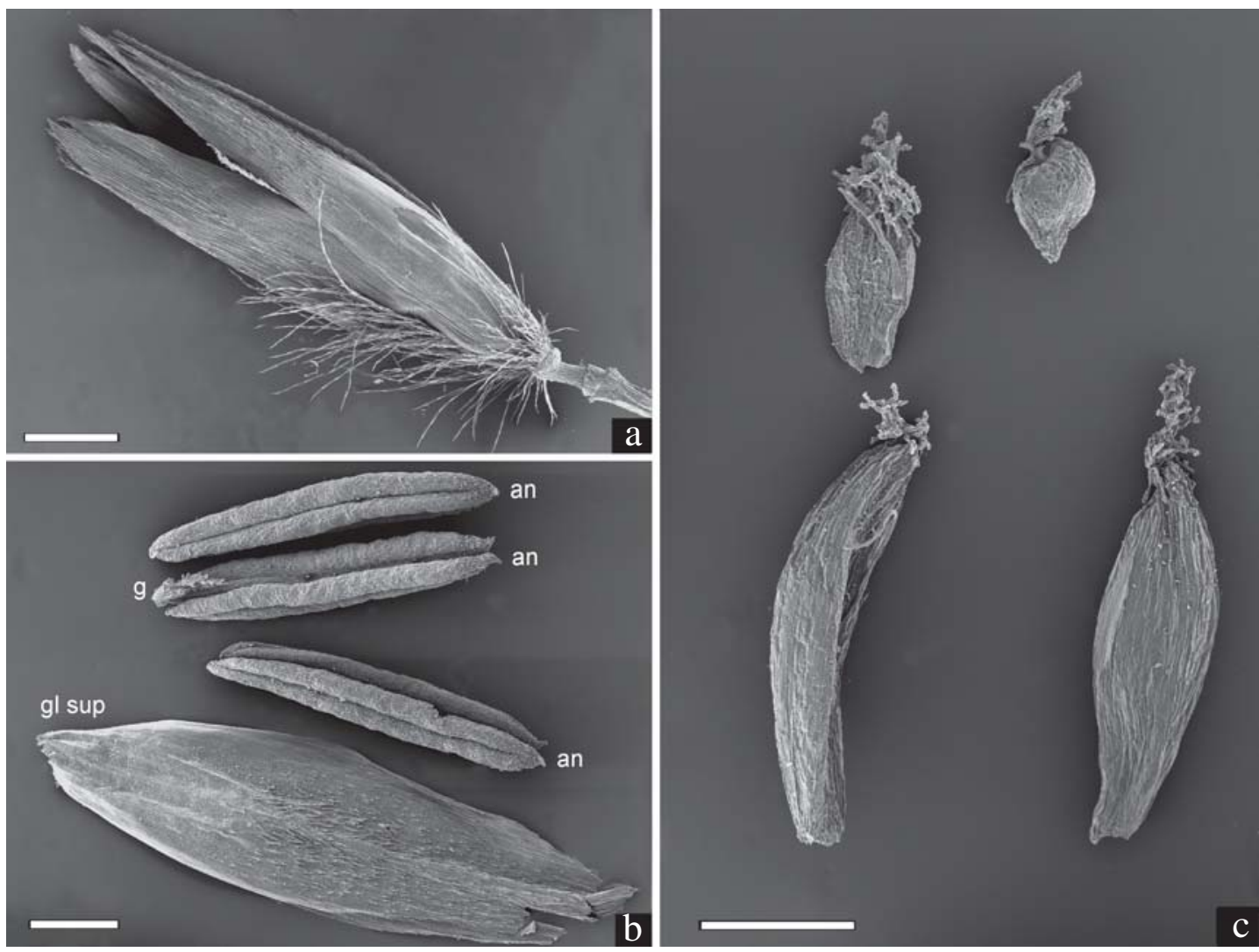

Figura 5. Deyeuxia eminens var. fulva. Microfotografías tomadas con microscopio electrónico de barrido. (a) Antecio, articulado al artejo inferior de la raquilla, se han cortado las glumas; (b) tres anteras, gineceo y gluma superior de la espiguilla, vista dorsal; (c) frutos en distintos estados de desarrollo. Abreviaturas: an, antera; gl sup, gluma superior; g, gineceo. Las reglillas equivalen a $500 \mu \mathrm{m}$.

Deyeuxia eminens var. fulva. Scanning electron micrographs. (a) Anthoecium, articulated with the lower joint of the rachilla, the glumes were cut; (b) three anthers, gynoecium and upper glume of the spikelet, dorsal view; (c) fruit in different stages of development. Abbreviations: an, anther; gl sup, upper glume; g, gynoecium. Rules $=500 \mu \mathrm{m}$.

- Deyeuxia eminens var. fulva (Griseb.) Rúgolo. Argentina. Provincia de Catamarca, Depto. Belén, Laguna Blanca, 4.200 msm., 16-III-1989, Reca et Ramadori 136 y 141 (SI).

- Jarava vaginata Phil. Argentina. Prov. de Catamarca, Depto. Antofagasta de la Sierra, Antofagasta de la Sierra, 4.050 msm., XII-1999, Rodríguez 25 (SI).

- Juncus arcticus Willd. var. mexicanus (Willd.) Baslev. Argentina. Prov. de Catamarca, Depto. Antofagasta de la Sierra, Antofagasta de la Sierra, 3.600 msm, XII-1998, Rodríguez 19 (SI).

- Phaseolus vulgaris L. Argentina. Prov. de Jujuy, Depto. Capital, Termas de Reyes, 1.500 msm, 17-II-1940, Burkart \& Troncoso s/n (SI 11203).

- Schoenoplectus asper Presl. Argentina. Prov. de Catamarca, Depto. Antofagasta de la Sierra, Antofagasta de la Sierra, 3.600 msm, XII1998, Rodríguez s/n (SI).

\section{Material arqueobotánico examinado}

El material analizado se encuentra depositado en el Instituto de Arqueología de la Universidad Nacional de Tucumán, bajo los números: 76 L4D, 107 L4C, 105 L4D, 106 M4C, 104 M4A, 68 M3C, 182 I3C, 412 I3D, 797 L3C, 797 L3C, 94 L3C, 906 L3C. 

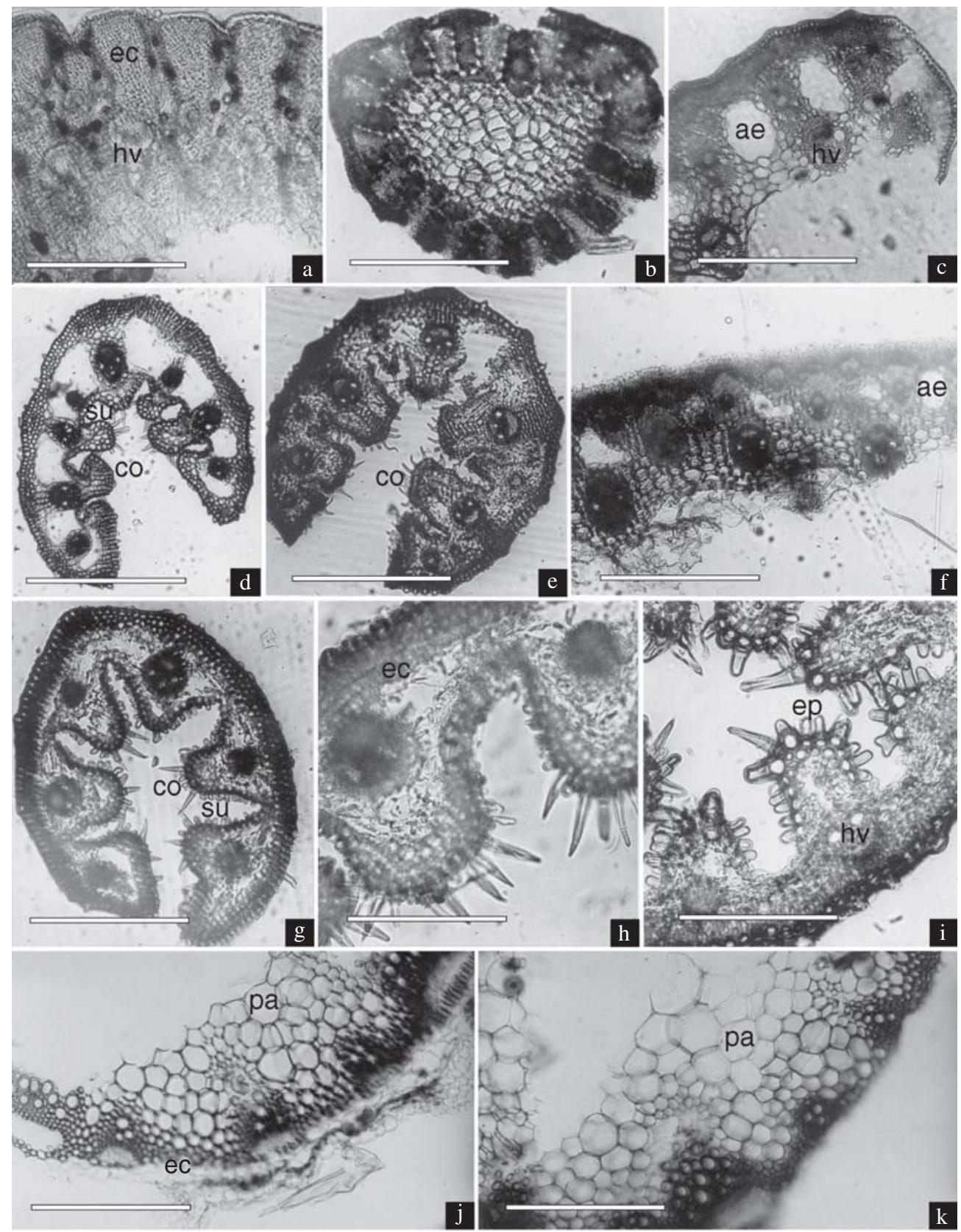

Figura 6. Anatomía de algunas especies recuperadas. Microfotografías tomadas con microscopio óptico. (a-b) Shoenoplectus asper. Tallo: (a) fragmento del corte transversal, material actual de referencia, Rodríguez $\mathrm{s} / \mathrm{n}$ (SI); (b) corte transversal, material arqueológico $\left(\mathrm{N}^{\circ} 68\right.$, microsector M3C). (c y f) Juncus arcticus var. mexicanus. Tallo: (c) fragmento del corte transversal, material actual de referencia, Rodríguez 19 (SI); (f) material arqueológico ( $\mathrm{N}^{\mathrm{o}}$ 107, microsector L4B); (d-e) Jarava vaginata. Hoja, corte transversal: (d) material actual de referencia, Rodríguez 25 (SI); (e) material arqueológico ( $\mathrm{N}^{\circ}$ 107, microsector L4B); (g-i) Deyeuxia eminens var. fulva. Hoja, corte transversal. Material arqueológico ( $\mathrm{N}^{\circ}$ 107, microsector L4B): (g) vista general; (h-i) detalle de costillas y surcos adaxiales con epidemis papilosa. (j-k) Chenopodium quinoa. Fragmento del corte transversal del tallo: (j) material actual de referencia, A.T Hunziker 2099 (SI); (k) material arqueológico ( $\mathrm{N}^{\circ}$ 68, microsector M3C). Abreviaturas: co, costilla; ae, aerénquima; ec, esclerénquima; ep, epidermis papilosa; hv, haces vasculares; pa, parénquima; su, surco. Las regillas equivalen a: a-c, f, j, $\mathrm{k}=400 \mu \mathrm{m} ; \mathrm{d}-\mathrm{e}=500 \mu \mathrm{m} ; \mathrm{g}=300 \mu \mathrm{m} ; \mathrm{h}=200 \mu \mathrm{m} ; \mathrm{i}=160 \mu \mathrm{m}$. Anatomy of some of the recovered species. Light microscope micrographs. (a-b) Shoenoplectus asper. Stem: (a) stem cross section, present day reference material, Rodríguez $s / n(S I)$; (b) stem cross section, archaeological material $\left(N^{\circ} 68\right.$, microsector M3C). (c and $f$ ) Juncus arcticus var. mexicanus. Stem: (c) stem cross section, present day reference material, Rodríguez 19 (SI); (f) archaeological material ( $N^{\circ} 107$, microsector L4B); (d-e) Jarava vaginata. Leaf, cross section: (d) present day reference material, Rodríguez 25 (SI); (e) archaeological material ( $N^{\circ}$ 107, microsector $\left.L A B\right)$; $(g-i)$ Deyeuxia eminens var. fulva. Leaf, cross section. Archaeological material $\left(N^{\circ}\right.$ 107, microsector L4B): ( $g$ ) general view; (h-i) epidermal cells with papillae, detail of adaxial ribs and furrows; $(j-k)$ Chenopodium quinoa. Stem cross section: (j) present day reference material, A.T. Hunziker 2099 (SI); ( $k$ ) archaeological material ( $N^{\circ} 68$, microsector M3C). Abbreviations: co, rib; ae, aerenchyma; ec, sclerenchyma; ep, epidermal cells with papillae; hv, vascular bundle; pa, parenchyma; su, furrow. Rules: $a-c, f, j, k=400 \mu \mathrm{m} ; d-e=500 \mu \mathrm{m} ; \mathrm{g}=300 \mu \mathrm{m} ; \mathrm{h}=200 \mu \mathrm{m} ; i=160 \mu \mathrm{m}$. 


\section{Resultados}

En la capa 3 del sitio PP4 se recuperaron restos pertenecientes a la familia Poaceae. Se hallaron grandes cantidades de espiguillas y algunas hojas (Figuras 2 y 5) y tallos aislados correspondientes a géneros de las familias Juncaceae y Cyperaceae (Figuras 6a-d).

La descripción anatómica foliar correspondiente al género Deyeuxia P. Bauv., familia Poaceae, concuerda con las realizadas anteriormente (Rodríguez et al. 2003), que se complementan con las ilustraciones (Figuras 6g-i). Las familias Juncaceae y Cyperaceae tienen muy escasa representación en esta capa y es probable que hayan sido llevadas al sitio junto con las gramíneas recolectadas, ya que crecen muy próximas unas de otras en un área de vegas. Las especies recuperadas pertenecientes a estas dos familias: Juncus arcticus var. mexicanus (Juncaceae) y Schoenoplectus asper (Cyperaceae), así como Jarava vaginata (Poaceae) y Chenopodium quinoa (Chenopodiaceae), se describen anatómicamente en este acápite (Figuras 6a-f, j-k). Se hallaron, además, restos de capítulos de la familia Asteraceae, semillas de la familia Fabaceae: Phaseolus vulgaris L. y Prosopis sp. (Figuras 3a-b) y cariopsis de Zea mays (Poaceae).

Las especies halladas se mencionan a continuación en relación con su representatividad en el sitio (Tabla 2). Se indica la probable procedencia, la cual se deduce a partir de las colectas realizadas y su distribución actual en el área:

\section{Familia Poaceae}

Deyeuxia eminens J. Presl. var. eminens. Nombre vulgar: "pasto huailla", "huaya", "iru", "sora sora" (Figura 2).

Procedencia probable: márgenes del río Punilla (vega), 3.500-3.600 msm.

Material hallado: ramas floríferas con espiguillas en antesis y espiguillas fructificadas, algunas con frutos inmaduros, hojas y parte basal de una planta. Números: 107 L4B, 73 L4C, 75 L4C, 68 M3C, 104 M4A, 106 M4C, Perfil s/n M4C.

Deyeuxia eminens var. fulva (Griseb.) Rúgolo. Nombre vulgar: "pasto de vega", "cebadilla de vicuña" (Figuras 2, 3e, 5 y 6g-i).

Procedencia probable: material de Herbario. Argentina. Prov. de Catamarca, Depto. Belén, Laguna Blanca, 4.200 msm, 16-III-1989, Reca et Ramadori 136 y 141 (SI).

Material hallado: ramas floríferas con espiguillas fructificadas, algunas con frutos inmaduros, hojas. Números: 135 L4B, 105 L4D, 76 L4D, Perfil s/n M4C.

Tabla 2. Especies halladas en las distintas cuadrículas y capas del sitio arqueológico PP4. Species recovered from the grids and layers of the PP4 archaeological site.

\begin{tabular}{|c|c|c|}
\hline Género-Especie-Variedad & Familia & Cuadrículas-Capa/Lente \\
\hline Deyeuxia eminens var. eminens & \multirow{10}{*}{ Poaceae } & L4, M3, M4. Lente 3b \\
\hline Deyeuxia eminens var. fulva & & L4. Lente $3 b$ \\
\hline Jarava vaginata Phil. & & L4. Lente $3 b$ \\
\hline \multicolumn{2}{|l|}{ Zea mays subsp. mays } & \\
\hline Amylacea o Capia & & L3. Lente 3b \\
\hline Amylacea o Capia & & I3. Lente 3b \\
\hline Amylacea o Capia & & I3. Lente 3b \\
\hline Amarillo & & L3. Lente 3b \\
\hline Pisingallo & & L3. Lente 3d \\
\hline Pisingallo & & I3. Lente $3 d$ \\
\hline Chenopodium quinoa & Chenopodiaceae & L4, L3. Lentes 3b y 3d \\
\hline Phaseolus vulgaris & \multirow{2}{*}{ Fabaceae } & M3. Lente 3b \\
\hline Prosopis sp. & & M3. Capa 3 \\
\hline Juncus arcticus var. mexicanus & Juncaceae & L4. Lente $3 b$ \\
\hline Schoenoplectus asper & Cyperaceae & L4. Lente $3 b$ \\
\hline
\end{tabular}


Jarava vaginata Phil. (Figuras 6d-e)

Procedencia probable: márgenes del río Punilla (vega), 3.500-3.600 msm y pajonal, 3.600-4.100 msm.

Material hallado: hojas. Número: 107 L4B.

Zea mays L. subsp. mays

Material hallado: cariopsis. Números: 797

L3C, 182 I3C, 412 I3D (Capia o Amylacea), 94

L3C (Amarillo), 906 L3C, 182 I3C (Pisingallo).

Especie cultivada. Puede tratarse de cultivo local o no local.

\section{Familia Chenopodiaceae}

Chenopodium quinoa Willd. (Figuras 3c-d, 4 y 6j-k)

Material hallado: ramificación de la inflorescencia, tallo florífero y semillas. Números: 107 L4B, 906 L3C.

Especie cultivada. Posiblemente fue un cultivo local.

\section{Familia Fabaceae}

\section{Phaseolus vulgaris L. (Figura 3a)}

Material hallado: semilla. Número: 68 M3C.

Especie cultivada. Cultivo no local, proveniente de zonas de menor altitud.

\section{Prosopis sp. (Figura 3b)}

Procedencia probable: Área Valliserrana. Especie no local.

Material hallado: semilla. Número: 68 M3C.

\section{Familia Juncaceae}

Juncus arcticus Willd. var. mexicanus (Willd.) Baslev. (Figuras 6c y f)

Procedencia probable: márgenes del río Punilla (vega), 3.400-3.600 msm.

Material hallado: tallos. Número: 75 L4C.

\section{Familia Cyperaceae}

Schoenoplectus asper Presl. (Figuras 6a-b)

Procedencia probable: márgenes del río Punilla (vega), 3.400-3.600 msm y Laguna de Antofagasta, $3.400 \mathrm{msm}$.

Material hallado: tallos. Número: 107 L4B.

\section{Descripción Anatómica de las Especies Recuperadas}

Las descripciones se realizaron a partir del análisis de material de referencia actual y del arqueológico.

Juncus arcticus var. mexicanus. Juncaceae (Figuras $6 \mathrm{c}$ y f)

Corte transversal. Tallo de contorno circular. Epidermis simple formada por una sola capa de células; esclerénquima desarrollado. Haces vasculares en dos o tres hileras con protoxilema, metaxilema y floema notorios; los haces en formación están incluidos en esclerénquima; todos ellos están rodeados por una vaina esclerenquimática. Parénquima fundamental escaso entre los haces vasculares. Espacios aeríferos que conforman el aerénquima, intercalados entre las hileras de haces. Médula hueca.

Schoenoplectus asper. Cyperaceae (Figuras 6a-b)

Corte transversal. Tallo de contorno cuadrangular. Epidermis simple con parénquima subepidérmico formado por una capa de células; esclerénquima con células de paredes gruesas en donde se originan los haces vasculares. Estos últimos están constituidos por dos vasos de metaxilema y uno de protoxilema poco desarrollados y por un floema notorio; cada haz vascular está rodeado por esclerénquima y, a su vez, por una capa de células parenquimáticas. Parénquima medular abundante.

Jarava vaginata. Poaceae (Figuras 6d-e)

Corte transversal de hoja. Transcorte en forma de "U". Costillas y surcos profundos en la cara adaxial. Costillas truncadas, grandes y pequeñas alternas; costillas marginales con las caras internas más o menos paralelas entre sí. Células epidérmicas adaxiales con pared externa tangencial engrosada; células buliformes conspicuas dispuestas en los surcos y ausentes en la cara abaxial. Estomas presentes en las caras laterales de los surcos. Pelos y aguijones en la cara adaxial. Células epidérmicas abaxiales con la pared tangencial externa algo engrosada. Generalmente 12 haces vasculares, seis primarios trabados por fibras hacia la cara abaxial y parénquima incoloro hacia la cara adaxial, los restantes secundarios, libres, más próximos a la cara abaxial. Vaina parenquimática desa- 
rrollada, sin cloroplastos especializados. Mesófilo con clorénquima difuso. Esclerénquima continuo formando paquetes subepidérmicos en la cara adaxial de las costillas; esclerénquima abaxial subepidérmico formado por tres o cuatro capas de fibras, continuo en vinculación con los haces primarios; esclerénquima marginal formado por dos o tres capas de fibras.

Chenopodium quinoa. Chenopodiaceae (Figuras $6 \mathrm{j}-\mathrm{k}$ )

Corte transversal de tallo (rama florífera) subcircular. Restos de epidermis seguidos por varias capas de células suberificadas. Parénquima incoloro con cristales o drusas. Tejido esclerenquimático dispuesto en varias capas continuas. Haces vasculares abiertos subtriangulares con floema y xilema. Parénquima medular abundante, entre los radios de floema y el xilema y hacia la parte medular del tallo con drusas dispersas.

\section{Distribución de las Especies Vegetales Arqueológicas en el Sitio}

El material arqueobotánico se concentra en siete microsectores (Figura 1b) correspondientes a cuatro cuadrículas-L3, L4, M3 y M4- de la capa 3b. En el microsector L4B se recuperó la mayor cantidad de espiguillas del género Deyeuxia, dispuestas en numerosas ramificaciones laterales de las inflorescencias (Figura 2b). Junto a las mismas se halló un cordel de lana y restos de Chenopodium quinoa (ramificación de la inflorescencia y tallo florífero conteniendo un fruto maduro con la semilla) (Figuras 3d y 4b). Se pudo apreciar la superficie de la rama florífera cubierta de pelos vesiculosos que le son propios. Los microsectores L4C (Figura 2a) y M4C siguen en importancia en relación con la cantidad de espiguillas del género $D e$ yeuxia. En el primero (L4C) se recuperaron también dos semillas de quínoa, cuyas características referidas a su forma lenticular de 2-3 mm de diámetro, con el embrión curvo y la radícula prominente, permiten identificarla como Chenopodium quinoa. Asimismo, en L3C se recuperó gran cantidad de semillas de Chenopodium quinoa (Figura 3c) y cariopsis de Zea mays. El resto de los granos de maíz se hallaron en I3C e I3D.

Otras agrupaciones con menor cantidad de espiguillas de Deyeuxia se encontraron en los microsectores M3C, M4A, M4C y L4D. En M3C, una semilla de Phaseolus vulgaris y otra de Prosopis sp. acompañan a dicha gramínea (Figuras 3a-b). Por último, algunas hojas aisladas de gramíneas de los géneros Deyeuxia y Jarava se hallaron en los microsectores M3C, M4A, M4C, L3B y L3D (Figuras 6d-e, g-i).

El número de ramificaciones laterales de inflorescencias de Deyeuxia recuperadas en cada microsector se detalla a continuación: L4B: 550 y siete (dos agrupaciones) (Figura 2b); L4C: dos agrupaciones, una con una sola ramificación y otra con un número muy elevado de las mismas que no fue posible contar, ya que se encuentran aglomeradas por vellones de lana (Figura 2a); L4D: tres; M3C: seis; M4C: 130; M4A: 108; M4C: 12, respectivamente.

Esta concentración de restos vegetales en un sector pequeño de la capa en estudio permite suponer que allí se habría realizado alguna actividad específica en relación con estos recursos. Además, a partir de la abundancia de órganos reproductivos de Deyeuxia eminens var. eminens y D. eminens var. fulva y la escasez de órganos vegetativos, es posible inferir la utilización de hojas o tallos de estas especies en alguna actividad específica y, a la vez, el descarte de espiguillas, tal como se plantea en las conclusiones. Es importante destacar, además, la asociación con semillas de quínoa, poroto y frutos (granos) de maíz.

\section{Conclusiones}

Los resultados obtenidos permitieron analizar el uso de los recursos vegetales en una unidad doméstica del sitio arqueológico PP4, así como la relación de complementariedad entre especies silvestres y cultivadas durante el lapso ca. 760-560 a.p. En la capa 3, lentes a/d, se halló un predominio de especies silvestres ( 6 taxones) junto a un número menor de especies cultivadas (3 taxones), siendo Chenopodium quinoa la más frecuente dentro de las últimas. De acuerdo con los resultados obtenidos, junto con las semillas de quínoa, poroto y Prosopis sp. y los frutos de maíz (Rodríguez y Aschero 2005b) fue hallada una significativa cantidad de ramificaciones de las inflorescencias con espiguillas y algunas hojas pertenecientes al género Deyeuxia (Poaceae). Otra gramínea (Jarava vaginata) y especies de las familias Juncaceae y Cyperaceae tuvieron escasa representación. 
Estos hallazgos apoyan la idea de la preparación del espacio doméstico para el procesamiento de determinados cultivos, concretamente para controlar el tostado de semillas de quínoa y/o su separación de las cenizas del fogón utilizado.

Es importante destacar la gran cantidad de espiguillas del género Deyeuxia recuperadas en la capa 3. El elevado número y el hecho de que sólo se hallaron las estructuras reproductivas acompañadas por ramificaciones y algunas hojas permiten suponer que se trata de material de descarte y selección de partes del vegetal para realizar alguna actividad (Figura 2). Estos datos apoyan la idea de que las cañas floríferas de Deyeuxia eminens pueden haber sido utilizadas para mover y tostar semillas de quínoa, tal como Villagrán et al. (2003) registran actualmente en Chile. Este probable uso vinculado con la dieta implica un cambio, ya que hasta el momento en PP4 distintas especies del género Deyeuxia fueron utilizadas en la confección de tecnofacturas (nudos, cordeles), camadas que conformaban los pisos de ocupación, así como también posibles "camas" y en la preparación de fardos funerarios (Rodríguez y Rúgolo de Agrasar 1999; Rodríguez et al. 2003).

Asimismo, es elevado el número de semillas de Chenopodium quinoa vinculadas con las estructuras de combustión de 3 b y 3 d identificadas como variedad doméstica (Bruno, comunicación personal 2003), asociadas a una gran cantidad de restos de Deyeuxia eminens. Esta asociación-Chenopodium quinoa/Deyeuxia eminens - relacionada con la dieta alimentaria no ha sido citada anteriormente para sitios arqueológicos del área de estudio.

Como se dijo en la introducción, en el sitio arqueológico Peñas Chicas 1.3 (Figura 1a), cercano a PP4, se recuperaron tallos de Chenopodium quinoa, en el nivel 2, cuadrícula L4, ca. 3.400 a.p. (Aguirre 2005). Asimismo, los estudios de microrrestos remanentes en la superficie de artefactos de molienda de Quebrada Seca 3 realizados por Babot (2004, 2005a, 2005b) señalan la presencia de Chenopodium cfr. quinoa y Zea mays, ca. 4.700-4.200 a.p.

Por otra parte, la asociación entre semillas de quínoa y restos de Deyeuxia eminens puede plantearse como una relación de complementación funcional. Las especies vegetales -silvestres o cultivadas- habrían jugado un papel importante en los contextos domésticos de los grupos cazadores recolectores, las silvestres desde ca. 9.000 años a.p. (Rodríguez y Rúgolo de Agrasar 1999; Rodríguez et al. 2003) y las cultivadas desde ca 4.700 a.p. (granos de almidón de Chenopodium cfr. quinoa) y ca. 4.500-4.200 a.p. (granos de almidón de Zea mays) (Babot 2004, 2005a, 2005b).

Las dataciones son aún más tempranas -ca. 6.000-6.100 a.p.- para Phaseolus sp. y otras especies de la familia Fabaceae recuperadas en Quebrada Seca 3 y en Cueva Salamanca 1 (Babot 2004, 2005a, 2005b). Sin embargo, se evidencia una continuidad temporal en el área desde el Holoceno Temprano, si se considera la antigüedad de otros sitios tales como Peñas Chicas 1.1-1.3, Punta de la Peña 9 y Punta de la Peña 4 (ca. 3.500-3.400-1.400500 a.p.) donde también se recuperaron micro y macrovestigios de las especies mencionadas.

Teniendo en cuenta que estos microvestigios fueron identificados en artefactos de molienda, resulta importante destacar el rol que estos recursos tenían en las prácticas económicas. Se destaca la profundidad y continuidad a través del tiempo de la complementación funcional entre especies silvestres y domésticas -sea como componentes utilitarios o de la ingesta- a través de las distintas estrategias de subsistencia de las antiguas poblaciones de la Puna Meridional.

Por último, es interesante destacar que estos hallazgos constituyen las primeras evidencias del uso de especies cultivadas en el área de estudio, los cuales pudieron ser locales o no locales, es decir, llevados desde zonas de menor altura. Sin embargo, como se dijo en la introducción, estas especies fueron de relativa importancia en la dieta de las antiguas poblaciones y pudieron haber sido un complemento.

Agradecimientos: Este trabajo se llevó a cabo con los Proyectos PICT 0988, PIP 03041, PIP 02515, CIUNT G205 y PEI Resolución 641 (Rodríguez). Queremos expresar nuestro agradecimiento a la Ing. Agr. A. M. Miante Alzogaray por la identificación del maíz y a la Dra. M. Bruno (University of Missouri, St. Louis) por la determinación, vía independiente, de las semillas de quínoa de la capa 3 b como variedad doméstica. A la Lic. A. Garbini por la diagramación de las figuras y a la Sra. Mariana Valente por su colaboración; al Lic. F. Tricarico del Servicio de Microscopía Electrónica del Museo de Ciencias Naturales Bernardino Rivadavia. Por último, agradecemos a los revisores del manuscrito, ya que con sus sugerencias nos ayudaron a enriquecer este trabajo. 


\section{Referencias Citadas}

Aguirre, M.G.

2005 Arqueobotánica de Peñas Chicas 1.3 Antofagasta de la Sierra, Catamarca. Tesis de grado en Arqueología. Universidad Nacional de Tucumán, Tucumán.

Babot, M.P.

2004 Tecnología y Utilización de Artefactos en el Noroeste Prehispánico. Tesis Doctoral. Universidad Nacional de Tucumán, Tucumán.

2005a Granos de almidón en contextos arqueológicos: posibilidades y perspectivas a partir de casos del Noroeste argentino. En Investigaciones Arqueobotánicas en Latinoamérica: Estudios de Casos y Propuestas Metodológicas, editado por B. Marconetto, N. Oliszewski y M.P. Babot. Centro Editorial de la Facultad de Filosofía y Humanidades. Universidad Nacional de Córdoba, Córdoba, en prensa.

2005b Plant resource processing by Argentinian Puna hunter-gatherers (ca. 7000-3200 B.P): microffosil record. Phytolitharien. Bulletin of the Society for Phytolith Research 17:9-10.

Cabrera, A.L.

1976 Regiones fitogeográficas argentinas. En Enciclopedia Argentina de Agricultura y Jardinería, editado por W.F. Kugler, pp. 1-85. Editorial Acme, Buenos Aires.

Cabrera, A.L. y A. Willink

1980 Biogeografía de América Latina. Secretaría General de la Organización de los Estados Americanos. Serie de Biología. Monografía N $^{\circ}$ 13, Washington D.C.

D'Ambrogio de Argüeso, A.

1986 Manual de Técnicas en Histología Vegetal. Editorial Hemisferio Sur S. A., Buenos Aires.

Hocsman, S., J.G. Martínez, M.F. Rodríguez y C.A. Aschero 2004 Obtención de recursos distantes en la porción meridional de los Andes Centro-Sur. Una visión desde la Puna argentina. Manuscrito en posesión de los autores.

Holmgren, P.K., N.H. Holmgren y L.C. Barnett 1990 Index Herbariorum, Part I. The Herbaria of the World ed 8, Reg. Veg. 120:1-693.

Rodríguez, M.F.

1996-1998 Propuesta metodológica para el análisis de macrovestigios vegetales. Presentación de un caso: Quebrada Seca 3, nivel 2b (12). Palimpsesto 5:238-248.

1999a Arqueobotánica de Quebrada Seca 3 (Puna Meridional Argentina): especies vegetales utilizadas en la confección de artefactos durante el Arcaico. Relaciones de la Sociedad Argentina de Antropología 24:159-184. 1999b Plant species (Families: Poaceae, Asteraceae, Fabaceae and Solanaceae) at an archaeological site of the Southern Argentine Puna. Journal of Ethnobiology 19:229-247.

2000 Woody plant species used during the Archaic Period in the Southern Argentine Puna. Archaeobotany of Quebrada Seca 3. Journal of Archaeological Science 27:341-361.

2004 Cambios en el uso de los recursos vegetales durante el Holoceno en la Puna meridional argentina. Chungara Revista de Antropología Chilena, Volumen Especial: 403-413.

Rodríguez, M.F. y C.A. Aschero

2005a Acrocomia chunta (Arecaceae) Raw material for cord making in the Argentinean Puna. Journal of Archaeological Science 32:1534-1542.

2005b Archaeological evidences of Zea mays L. (Poaceae) in the Southern Argentinean Puna (Antofagasta de la Sierra, Catamarca. Manuscrito en posesión de los autores.

Rodríguez, M.F. y Z. Rúgolo de Agrasar

1999 Deyeuxia eminens (Poaceae: Agrostideae) en un sitio arqueológico de la Puna Meridional Argentina (Provincia de Catamarca). Darwiniana 37:229-242.

Rodríguez, M.F., Z.E. Rúgolo de Agrasar y C. Aschero

2003 El género Deyeuxia (Poaceae, Agrostideae) en sitios arqueológicos de la Puna meridional argentina. Provincia de Catamarca. Chungara Revista de Antropología Chilena 35:51-72.

Rossen, J. y C. Ramírez

1997 Observations on the Present-Day (1983) economic plants in the Monte Verde area and their archaeological implications. En Monte Verde. A Late Pleistocene Settlement in Chile. Volume 2. The Archaeological Context and Interpretation, editado por T.D. Dillehay, pp. 307-329. Smithsonian Institution Press, Washington and London.

Troll, C.

1958 Las culturas superiores andinas y el medio geográfico. Revista del Instituto de Geografía 5:3-55.

Villagrán, C., M. Romo y V. Castro

2003 Etnobotánica del sur de los Andes de la primera Región de Chile: un enlace entre las culturas altiplánicas y las de quebradas altas del Loa Superior. Chungara Revista de Antropología Chilena 35:73-124. 
